\title{
Subdural Hemorrhage
}

National Cancer Institute

\section{Source}

National Cancer Institute. Subdural Hemorrhage. NCI Thesaurus. Code C50759.

Bleeding between the dura mater and the brain, usually secondary to a tear of the bridging vein. 